\title{
SABERES EM MOVIMENTO NA BIBLIOTECA MUNICIPAL DE JUÍNA - MT
}

\author{
KNOWLEDGE IN MOTION AT THE MUNICIPAL LIBRARY \\ OF JUÍNA - MT
}

Marinete Luzia Francisca de Souza'

1 Professora Adjunta II na Universidade Federal de Mato Grosso, Campus Universitário do Médio Araguaia e no Programa de Pós-graduação em Estudos de Linguagem, do Campus de Cuiabá. Licenciatura em Letras - Português e Literaturas; Mestre em Estudos Literários pela Universidade Federal de Mato Grosso. Doutora em Literaturas de Língua Portuguesa (investigação e ensino), pela Universidade de Coimbra. Publicou, em co-autoria, com Célia Maria Domingues da Rocha Reis, a obra Pedro Casaldáliga e poética de emancipação, pela EDUFMT, em 2014. Link para o Lattes: http:// lattes.cnpq.br/846488656238626, Orcid: https://orcid.org/0000-0001-8801-9694, marineteluzia2@ gmail.com. 
RESUMO: Neste artigo, examinamos o projeto "Arte, Leitura e Cultura, uma bela mistura", sediado na Biblioteca Municipal Profa. Maria Santana, em Juína - MT. O projeto tem recebido reconhecimento nacional e internacional por meio da participação em eventos e de premiações. Visa-se analisar o papel das ações desenvolvidas para a democratização de conhecimentos e a concepção de leitura que subjaz ao projeto analisado. Para a realização desta análise, entrevistamos a idealizadora do projeto e as ações desenvolvidas. Com foco, perpassamos a função das bibliotecas e o conceito de letramento, segundo Pereira (2009), Scribner e Cole (1981) utilizados como norteadores para o balizamento teórico deste estudo.

PALAVRAS-CHAVE: Projeto de leitura; Bibliotecas; Democratização de saberes; Letramento.

ABSTRACT: In this article we examine the project "Art, Reading and Culture, a beautiful mixture", which takes place at the Prof ${ }^{a}$. Maria Santana Municipal Library, in Juína-MT. The project has received national and international recognition by means of participation in events and awards. The aim is to analyze the role of the actions developed for the democratization of knowledge and the concept of reading that underlies the project. To carry out this study, we conducted an interview with the creator of the project, and the actions developed in it. With this focus, we go through the function of libraries and the concepts of literacy, having Pereira (2009), as well as Scribner and Cole (1981) as guidelines for the theoretical framework of this study.

KEYWORDS: Reading Project; Libraries; Democratization of knowledge; Mediation. 


\section{INTRODUÇÃO}

Toda biblioteca tem a função de difundir não apenas a informação, mas também o conhecimento. Já a biblioteca pública cumpre o papel específico de garantia do acesso (no sentido de democratização) aos saberes. Segundo o Manifesto da UNESCO Sobre Bibliotecas Públicas (1994): “A biblioteca pública, porta local de acesso ao conhecimento, constitui um requisito básico para a aprendizagem ao longo da vida, para a tomada independente de decisões e para o progresso cultural do indivíduo e dos grupos sociais".

No caso da Biblioteca Municipal Profa. Maria Santana, do município de Juína, estado de Mato Grosso, aqui analisada, houve articulação para que fosse apoiada pelo Conselho Municipal de Cultura e por outros entes públicos locais: Grupo de Idosos

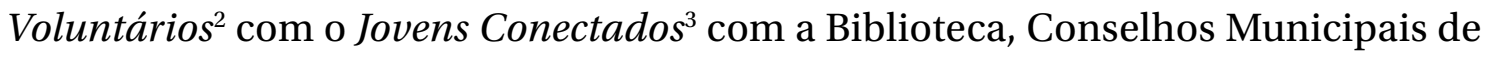
Direitos, Secretaria Municipal de Educação (para revitalização das bibliotecas escolares), Faculdade AJES, Ministério Público do Trabalho e da Justiça do Trabalho, Instituto Federal de Mato Grosso, CRAS, CREAS, Associação Comercial e Câmara de Dirigentes e Lojistas de Juína.

Foram realizados levantamentos para determinação das demandas municipais para elaboração Planejamento Estratégico do Município de Juína, quando segmentos diferenciados da sociedade civil se uniram para criar projetos como oficinas para docentes autóctones na aldeia Pé de Mutum, do povo Rikbatsa, os projetos "Amigo do Livro e da Leitura" e o "Jovens Conectados com a Biblioteca".

2 Trata-se de idosos que atuam como voluntários na BMJ lendo histórias para as crianças que a frequentam.

3 “Os Jovens Conectados são grupos de jovens usuários da biblioteca que contribuem como voluntários para organizar ações da biblioteca e de fomento à leitura. Usam o espaço para se reunir, organizar, ler, debater obras literárias, realizar ensaios artísticos e etc.", afirma a idealizadora do projeto, Patrícia Itaibele Gomes Pereira. Além de idealizadora do projeto, Patrícia Itaibele Gomes Pereira é pedagoga, membro do Conselho Estadual de Cultura, Coordenadora Nacional da Pastoral da Juventude- Oeste II, atua na comissão Gestora da Biblioteca Municipal de Juína. Foi Coordenadora de Fomento à Leitura do Município de Juína de 2017 a 2019. É ainda membro do Partido dos Trabalhadores. 
A Biblioteca Municipal de Juína (doravante BMJ) é vinculada ao Sistema Estadual de Bibliotecas Públicas de Mato Grosso (SEBPMT). A BMJ existe há mais de três décadas e, atualmente, destaca-se por fomentar projetos que objetivam levar o leitor para dentro da biblioteca, mas também por fazer com que ela circule entre a população em eventos ou ainda pelo projeto delivery, que teve início durante a pandemia de Covid-19 e permite que os usuários peçam livros que são encaminhados pelos servidores da Biblioteca a suas casas, após quarentena e desinfecção.

Em agosto de 2019, representantes do município apresentaram o programa na abertura do $11^{\circ}$ Seminário Internacional de Bibliotecas Públicas e Comunitárias "Biblioteca Viva", que ocorreu em São Paulo, no Centro de Convenções Rebouças. Entre os prêmios ${ }^{4}$ recebidos pela Biblioteca Municipal Profa. Maria Santana estão o MuniCiência, Ciclo 2019-20206 , coordenado pela Confederação Nacional dos Municípios (CNM). Conforme se pode ler no site da CNM, "É uma iniciativa da Confederação Nacional de Municípios (CNM) para identificar, reconhecer e reaplicar práticas inovadoras em gestão municipal"7 . Trata-se, portanto, de ações consideradas inovadoras selecionadas por meio de chamada pública às quais os municípios se candidatam. As ações, além de inovadoras, devem ser consideradas adaptáveis às condições locais. Entre as atividades desenvolvidas pela BMJ está o Biblioteca Delivery, uma parceria

4 Em 2018, a BMJ obteve o segundo lugar no concurso nacional “Conecta Biblioteca”, que premia as 10 bibliotecas públicas brasileiras que mais contribuem para o avanço dos Objetivos do Desenvolvimento Sustentável da ONU e para a transformação social de suas comunidades. O Conecta Biblioteca é coordenado pela Organização Não Governamental RECODE e pela Caravan Studios, com fomento da Fundação Bill e Melinda Gates.

5 No total, a BMJ recebeu nos últimos quatro anos os seguintes prêmios: 2018 - Vencedor do Programa Nacional Conecta Bibliotecas da ONG RECODE do Rio de Janeiro por atingir os Objetivos da Agenda 2030 da ONU - Organização das Nações Unidas; 2019 - Reconhecimento do Governo de São Paulo como uma das 15 Melhores Práticas de Bibliotecas da América Latina; 2019 - Prêmio Nacional IPL - Retratos da Leitura recebido em São Paulo; 2020 - Prêmio MuniCiência, promovido pela Confederação Nacional dos Municípios - CNM.

6 Pode-se saber mais sobre o prêmio em: https://youtu.be/mrcDYZA7Q64.

7 http://www.municiencia.cnm.org.br/principal. Consulta realizada em 10 de janeiro de 2021. 
com a Justiça do Trabalho e o Ministério Público do Trabalho durante a pandemia da COVID-19, que foi premiado em 2020 pelo Programa Ibero-americano de Bibliotecas Públicas, IBERBIBLIOTECAS ${ }^{8}$. O prêmio destina-se a alternativas inovadoras no incentivo a leitores com suporte do Centro Regional para el Fomento del Libro em América Latina y el Caribe, apoiado pela UNESCO. O projeto premiado dedica-se à entrega de livros nas casas dos leitores com a finalidade de garantir-lhes não apenas leituras, mas momentos de diversão e contato com diversos saberes, assegurando sua democratização.

O modelo tradicional de biblioteca pública vem sendo questionado desde algum tempo, e em seu lugar está surgindo o projeto de um ambiente informacional, social, lúdico, de circulação de variados conhecimentos. Raymond Williams (2007) defende que esse novo paradigma é relativamente complexo porque perpassa variados saberes postos em contato e em utilização. No estado de Mato Grosso, identificam-se tentativas de atualização dos acervos, oferta de acesso às tecnologias de informação em alguns municípios e tramitação do Plano Estadual do Livro, Leitura, Literatura e Biblioteca de Mato Grosso (PELLLB-MT). O referido Plano prevê a compra de equipamentos como computadores, instalação de redes de internet, digitalização dos acervos e incentivo à produção e à circulação do livro. Outra ação interessante é o Programa Estadual de Revitalização de Bibliotecas, ou Revita Bibliotecas ${ }^{9}$, do qual a BMJ participa.

Para além disso, a biblioteca pública atende a um público heterogêneo e, por

8 A ata do prêmio pode ser consultada em_ https://www.iberbibliotecas.org/wp-content/ uploads/2020/11/Acta_por_2020.pdf

9 O projeto é realizado pela Secretaria Estadual de Cultura de Mato Grosso e promove cursos de atualização de bibliotecários, oficinas voltadas ao incentivo e à valorização da leitura e da escrita, leitura em braile e entrega de kits de modernização. Conforme menciona Waldineia Ribeiro de Almeida, coordenadora do Sistema Estadual de Bibliotecas Públicas de MT, no site da Secretaria Estadual de Cultura do Estado de Mato Grosso: “O projeto RevitaBibliotecasMT é uma iniciativa do Sistema Estadual de Bibliotecas Públicas de Mato Grosso que propõe ativar, revitalizar, modernizar e ressignificar bibliotecas públicas de Mato Grosso para estruturar, ampliar, melhorar o acesso à informação, incentivo ao livro e leitura, engajamento da comunidade e inclusão social". In: http://www.mt.gov. br/rss/-/asset_publisher/Hf4xlehM0Iwr/content/id/12557353. Consulta em 20 de julho de 2020. 
isso, tem assumido para si a tarefa de promover atividades culturais e de mediação de leitura. Esse emprego é também expresso no manifesto da UNESCO de maneira que a biblioteca venha a exercer atividades equitativas de leitura. Além disso, a biblioteca contribui para o desenvolvimento da organização de pensamentos sofisticados por parte do leitor. Ou melhor, o hábito de ler contribui para o letramento que ocorre pelo contato diário com as tecnologias de informação, com o livro e com outros materiais, impressos ou não.

Benavente (1996) argumenta que o letramento está relacionado com habilidades de leitura, cálculo e uso de materiais escritos. Nessa mesma direção, Scribner e Cole (1981:236) acentuam a correlação entre saber ler e fazer uso desse tipo de leitura: "literacia não é simplesmente saber ler e escrever um texto em particular, mas aplicar este conhecimento para propósitos específicos em contextos de uso específicos".

O conceito

refere-se àquelas práticas sociais em que os leitores e/ou ouvintes vão além da mera utilização dos textos para construírem significado, realizando deliberadamente uma análise questionadora dos significados aí presentes e da influência que essas representações têm sobre si próprios nos contextos sociais, bem assim como mobilizando essa informação para denunciar e subverter publicamente a presença desse poder social oculto. (PEREIRA, 2009: 19)

Nesse sentido, as bibliotecas, desenhadas para a garantia de ambientes de letramento, favorecem maior acesso ao mundo atual que exige cada vez mais habilidade de leitura e escrita e domínio de tecnologias informacionais.

Com as atuais configurações dos sistemas de comunicação e informação, as bibliotecas cumprem a função de letrar nas tecnologias dos conhecimentos e continuar trabalhando com o livro, visto que a alfabetização continua a ser o ponto de partida para todos os demais letramentos. Acresce-se a isso o não distanciamento da memória cultural e das artes que, somadas às tecnologias mencionadas e ao conhecimento das línguas estrangeiras, permite aos cidadãos terem domínio de técnicas e conhecimentos que facilitarão suas vidas, incluindo-se questões como o imaginário e a criatividade. Isso requer dos agentes públicos esforços no sentido de favorecer 
contínuo letramento literário e digital, além da oferta de atividades de mediação e disponibilização de acervos atualizados.

\section{O PROJETO ARTE, LEITURA E CULTURA, UMA BELA MISTURA}

Este artigo objetiva analisar o trabalho desenvolvido na Biblioteca Municipal Profa. Maria Santana, de Juína-MT, que vem resultando desde 2017 na revitalização e na formação da comunidade de leitores naquele município. Em entrevista realizada em junho de 2020 (por meio de roteiro de perguntas respondidas por escrito), Patrícia Itaibele Pereira $^{10}$, uma das idealizadoras do Projeto, afirma que, com ele, teve início todo o trabalho de transformação física e conceitual dessa biblioteca, com o suporte do SISEB - Sistema Estadual de Bibliotecas. O programa conta com uma Coordenação Municipal de Fomento à Leitura, focada em revigorar os ambientes de leitura do Município, transformando-os em espaços culturais, de expressões artísticas, e, sobretudo, de leitura, a começar pelas bibliotecas escolares e comunitárias". Nota-se então que questões artísticas, de acesso à informação e ao conhecimento, estão relacionadas ao trabalho realizado na Biblioteca Municipal de Juína. Há também um entendimento de que o trabalho com as bibliotecas deve ocorrer em vários espaços dedicados à leitura e à existência de múltiplos tipos de bibliotecas, por isso, fomentam-se aquelas escolares, as comunitárias e a municipal. Com o tempo, informa a entrevistada, houve interligação do projeto ao Programa Nacional Conecta Biblioteca e ao Programa de Desenvolvimento Integrado (PDI) do Tribunal de Contas do Estado de Mato Grosso, que passaram a dar suporte técnico, consultorias, formação e financiamento ao projeto. Trata-se de uma concepção de projeto participativo, no qual a população foi sendo consultada sobre aquilo que desejava, um modo de democratizar não apenas o conhecimento, mas também as decisões políticas acerca dele.

10 Pedagoga e uma das idealizadoras do Projeto Arte, leitura e cultura, uma bela mistura, Coordenadora Regional da Pastoral da Juventude. Membro do Partido do Trabalhadores do Conselho Municipal de Cultura de Juína. 
O projeto foi criado num contexto de interesse da entrevistada pela leitura (já que é pedagoga e trabalha com crianças) e do Secretário Adjunto de Cultura da cidade de Juína, José Adriano de Souza, pela gestão cultural de Juína no início da atual administração daquele município, e coincidiu com o período em que a Secretaria Estadual de Cultura desenvolvia o Programa Estadual de Revitalização de Bibliotecas RevitaBibliotecasMT. Convém lembrar que o RevitaBibliotecas e outras ações estaduais, como o Plano Estadual do Livro, Leitura, Literatura e Biblioteca de Mato Grosso (PELLLB-MT), em processo de análise pela Assembleia Legislativa do Estado de Mato Grosso, indicam que há, nesse momento, movimentos em favor da cultura que ultrapassam as fronteiras do Município de Juína.

De acordo com a ex-Coordenadora de Fomento à Leitura do Município de Juína, o objetivo inicial era melhorar as instalações e oportunizar ambientes aconchegantes de leitura aos usuários. Com o cadastramento da BMJ no Programa Nacional Conecta Biblioteca, em maio de 2017, informa Patrícia Itaibele Pereira, o desejo de criar o mencionado espaço ganhou força, e objetivos como a revitalização da biblioteca e sua informatização foram alcançados. A BMJ passou a ser um espaço no qual atores sociais de diversos setores se encontram para consultas à comunidade sobre as políticas de leitura em Juína.

Tal projeto desencadeou a criação de uma Coordenação Municipal de Fomento à Leitura, conforme Patrícia Itaibele Pereira, "focada em transformar todos os ambientes de leitura do município, transformando-os em espaços culturais de todas as expressões artísticas, começando pelas bibliotecas escolares e comunitárias”. A biblioteca passou a abrigar os diversos atores sociais de diversos segmentos e organizações a fim de realizar a consulta à comunidade. Isso resultou na edificação de uma biblioteca descentrada. Patrícia Itaibele Pereira afirma:

A mudança de conceito possibilitou uma biblioteca livre e aberta, sem apenas um endereço físico, mas que rompe barreiras geográficas. A Biblioteca está presente em todos os eventos municipais, se destacando as seguintes versões: BiblioCity - Cidade Educadora durante a maior festividade municipal, o aniversário de emancipação política de Juína; BiblioFolia durante as festividades de Carnaval; BiblioRoça durante o Sarau de arte, culinária e artesanato; BiblioCowntry durante a Expoju. 
A BiblioCowntry acontece durante as festividades agropecuárias de Juína que ocorrem uma vez por ano e recebem o nome de Expoju. É montada uma biblioteca durante a exposição com temática rural: livros sobre fazendas, plantio, animais etc. A BiblioFolia ocorre durante o carnaval. Nela são realizadas atividades relacionadas ao carnaval: leituras de textos informativos e literários sobre o tema e canções carnavalescas. Fantasiam-se crianças e adultos e media-se o contato com o texto escrito, além de se deixar o livro à disposição da comunidade. A Cidade Educadora, antes BiblioCity (cidade da biblioteca), consiste na realização de um trabalho de conscientização de vários atores sociais no sentido de que haja uma compreensão de que todos são responsáveis pela educação e que se pode ler e aprender em todos os espaços. Conta-se com parceiros como o AJES - Instituto Superior de Educação do Vale do Juruena e o Campus do Instituto Federal de Mato Grosso de Juína.

A presença do livro nos diversos espaços e momentos mencionados pela entrevistada apresenta potencial de mudar a relação que os habitantes de um determinado lugar têm com o livro e com a leitura, visto que não estão mais distante deles. Por outro lado, ainda que os habitantes de um município não se locomovam por falta de recursos financeiros até os locais das festas e exposições mencionadas, as crianças terão acesso ao livro nas bibliotecas escolares, visto que, com raras exceções, toda criança frequenta o sistema escolar. A partir deste ponto, entendemos que surge uma nova concepção de leitura como algo que se dá em todo lugar e que está relacionada com o lúdico, como afirma Pereira: "a leitura passou a ter espaço em todos os ambientes e não apenas reduzida ao livro, mas mostrando suas diversas faces, construindo uma memória afetiva e efetiva para quem a experimenta." Quer isso dizer que, se ligada a atividades prazerosas, a leitura abrange não apenas o campo do conhecimento, mas das experiências relativas ao que vivenciamos e seus significados. As atividades de leituras ligam-se ao projeto aqui analisado e a outros serviços como contação de histórias, jogos, além de acesso às tecnologias de informação. E o trabalho se amplia:

Atrelada a essas atividades pontuais, existe a organização da sociedade civil com o Conselho Municipal de Livro, Leitura, Literatura e Bibliotecas, o Sistema Municipal de Bibliotecas que integra todos os espaços de bibliotecas do município, cursos gratuitos, acesso à 
internet liberado na sede, impressões e cópias gratuitas, Rodas de Conversa e diversos serviços que garantam o direito à informação. Além dessas, contamos com a criação da BiblioOca junto à associação indígena Rikbaktsa, a primeira em seu formato. Além da Biblioteca no Centro Municipal de Reeducação com livros e cursos aos reeducandos. ${ }^{11}$

Considerando o exposto, notamos que as atividades desenvolvidas na Biblioteca Municipal de Juína estão sendo direcionadas de acordo com as atuais políticas do livro e ainda contribuindo para a aprovação de leis e normativas para as políticas de leitura no município.

Dentre elas, estão: Lei Municipal 1.821/2018, que institui o PMLLLB - Plano Municipal do Livro, Leitura, Literatura e Bibliotecas e a PML - Política Municipal do Livro, aprovada pela Lei Municipal 1.898/2019, que garante o incentivo à produção editorial local e o desenvolvimento da economia do livro no município e torna obrigatória a aquisição anual de livros de autores e escritores mato-grossenses ou residentes no estado.

Em vídeo ${ }^{12}$ gravado para o Prêmio MuniCiência 2020, Patrícia Itaibele Pereira acentua que a iniciativa usa como método a agregação de várias ações com a finalidade de evidenciar a potencialidade do ser humano. Por outro lado, Silvia Oliveira acentua que o programa "reúne diversas linguagens com o objetivo de fomentar as ações da biblioteca e do incentivo à leitura" inspirado no conceito de bibliotecas parque desenvolvido na cidade do Rio de Janeiro. O conceito consiste na agregação de variadas linguagens artísticas dentro de um único local e ou em uma única atividade. Por seu turno, usuárias da biblioteca destacam, em seus depoimentos, o fato de o livro permitir-lhes o acesso a outros mundos e de a biblioteca favorecer a imaginação e o contato com outras artes.

Tais políticas centradas no livro e na leitura, somadas às atividades de mediação cultural em eventos ou criação de espaços de leitura, favorecem o surgimento de uma comunidade de leitores.

11 Segundo Patrícia Itaibele Gomes Pereira, em entrevista realizada em julho de 2020.

12 Disponível em_https://youtu.be/mrcDYZA7Q64 
A esse propósito, Maria Helena Martins (1994) considera que a leitura pode concorrer para que a formação do ser humano ocorra em sua integralidade, pois ela pode abranger vários aspectos como o sensorial, o emocional e o racional. $\mathrm{O}$ primeiro deles tem início nos primeiros anos e acompanha a pessoa em sua trajetória de vida. Essa forma de leitura está relacionada aos sentidos por referir-se ao reconhecimento de cores, texturas, formatos etc.; o segundo diz respeito às emoções desencadeadas no contato com textos de vária ordem, principalmente com os ficcionais. Na leitura racional, realizam-se operações relacionadas à decodificação, interpretação, análise e síntese.

As relações entre a leitura e o acesso universal ao conhecimento são algo a ser destacado na atuação da Secretaria Municipal de Cultura de Juína, visto que democratiza o saber. A esse propósito, Antonio Candido afirma no seu conhecido texto $O$ Direito à Literatura (2004, p.191) "que a luta pelos direitos humanos abrange a luta por um estado de coisa em que todos possam ter acesso à cultura”.

Nesse mesmo sentido, Todorov (2009) aborda a formação literária na sua relação com a formação de mulheres e homens quando afirma, em A Literatura em Perigo (TODOROV, p. 22): “a literatura não nasce no vazio, mas no centro de um conjunto de discursos vivos, compartilhando com eles numerosas características; não é por acaso que, ao longo da história, suas fronteiras foram inconsistentes". Nota-se assim que, tanto o acesso à escrita como o próprio livro permitem ao cidadão a participação numa comunidade de leitores e o contato com estéticas formadoras da sensibilidade para as artes, as humanidades e as relações interpessoais.

Os saberes humanísticos cumprem a função de facilitar as relações humanas por colaborarem com o amadurecimento intelectual e emocional de crianças e jovens, daí que, ao promover pontos de leitura e atividades de mediação cultural, a Biblioteca Municipal de Juína contribui para aquilo que Antonio Candido chamou "direito à literatura". Esse direito se estende à informação e à tecnologia, visto que a referida biblioteca é membro do Conecta Biblioteca,um projeto da Organização RECODE, que fomenta bibliotecas selecionadas pela referida ONG e oferece a elas acesso à leitura via digital. Trata-se de uma organização internacional que fomenta bibliotecas em variados países e que premiou, em 2018, o projeto aqui analisado, e vem lhe oferecendo suporte. 
Nesse contexto, o incentivo à leitura via bibliotecas públicas requer também, com a emergência de suportes informacionais (que exigem cada vez mais técnicas leitoras adequadas para o domínio das tecnologias em informação e comunicação), suportes técnicos e equipamentos e formação de suas equipes, o que vem sendo oferecido à equipe da Secretaria de Cultura de Juína pela RECODE. Com as tecnologias informacionais, emergem outros códigos e linguagens, as novas textualidades, procedentes e precedentes do universo digital que também implicam letramento.

\section{SABERES EM MOVIMENTO: MEDIAÇÃO CULTURAL NA BIBLIOTECA MUNICIPAL DE JUÍNA}

Os equipamentos públicos, por via de sua própria constituição, como organismo de serviço ao público, adquirem importante papel no que respeita à mediação cultural impressa, virtual e oral do saber. Consequentemente, essas instituições têm uma tarefa a desenvolver nas comunidades locais para que se permita que todos possam ter acesso ao conhecimento e que, por seu intermédio, jovens e adolescentes de diversos espaços sociais ingressem no mundo considerado letrado, além de favorecer a entrada de "sabedores" advindos de culturas postas à margem, como as orais, como as indígenas, e seu reconhecimento como produtoras de bibliotecas com fins ao seu reconhecimento como epistemologias. 


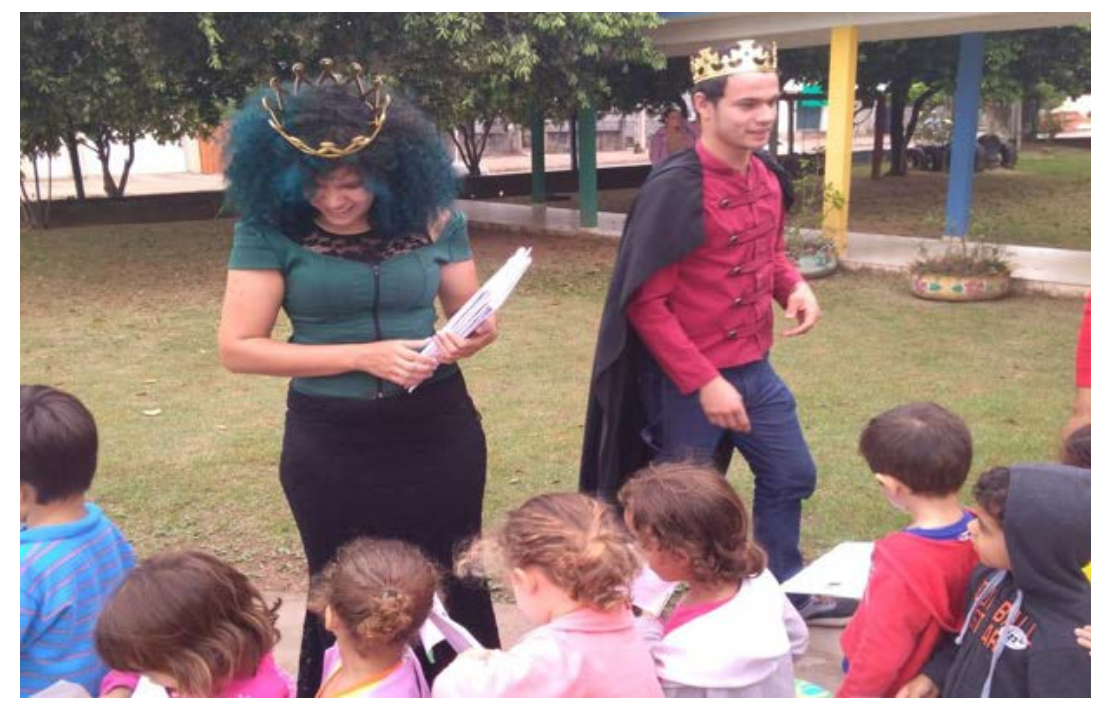

Figura 1: Entrega de livros recebidos do Itaú Social, 2019.

Crédito: Antônio Ribeiro (fotógrafo)

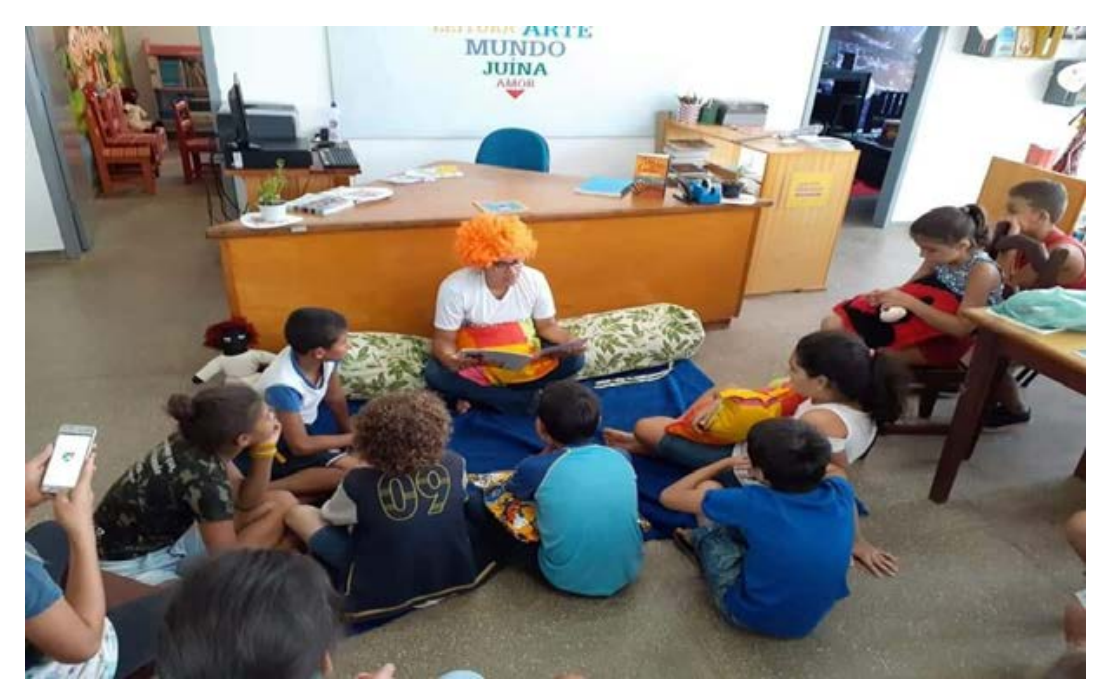

Figura 2: Atividade de contação de história na Biblioteca Municipal de Juína

Crédito: Antônio Ribeiro (fotógrafo)

Dentre as atividades desenvolvidas na Biblioteca Municipal de Juína estão, como informa a entrevistada, "pintura facial, desenhos, brincadeiras infantis, atividades lúdicas, leitura e contação de histórias, jogos de tabuleiro e baralho, distribuição de mudas de árvores nativas, campanhas de prevenção, reciclagem etc.."

Segundo relatado por Patrícia Itaibele Pereira, os resultados da revitalização 
da BMJ fizeram com que a quantidade de leitores aumentasse significativamente, de maneira que a biblioteca conta hoje com uma média de mais de cinco mil leitores ativos, nem todos com carteira de leitor, o que permite a retirada de livros da Biblioteca, mas fazendo uso de seu espaço. Nas ações desenvolvidas fora do espaço físico, o público varia, de acordo a dimensão do evento, entre 500 a 10 mil pessoas (no aniversário da cidade, por exemplo). ${ }^{13}$

Após aquisições recentes, o acervo da BMJ consta de 15 mil títulos divididos entre a Biblioteca Pública Maria Santana do Nascimento e o Chalezinho da Leitura, voltado ao público infantil exclusivamente. Além disso, há a política pública de aquisição de acervo anual, voltada aos autores mato-grossenses e Literatura em geral.

Ao ser questionada sobre a relação entre desempenho escolar dos estudantes que frequentam a Biblioteca, a entrevistada afirmou: "ainda não temos tabulados os resultados decorrentes das provas de desempenho escolar, porém, temos efetiva e gradativa participação das escolas nas atividades da Biblioteca, projetos escolares são apresentados nela, a melhoria e procura da leitura saltou mais de $60 \%$ depois de iniciado o projeto"

Tais atividades enquadram-se naquilo que conhecemos como mediação da leitura. Segundo Gomes,

[...] a mediação relaciona-se com a comunicação e se caracteriza como um processo de intersubjetividades, resultante da negociação e da disputa de sentidos, que permite aos sujeitos ultrapassar e interpenetrar esses sentidos e gerar novas significações. A mediação se opõe ao imediatismo, porque demanda o jogo dialético, sem o qual inexiste. (GOMES, 2010, p. 88)

13 Um fato interessante sobre os resultados do projeto Arte, leitura e cultura, uma bela mistura é a presença de notícias em jornais do estado de Mato Grosso sobre a biblioteca de Juína, destacando-se o reconhecimento pelo trabalho realizado assim como a posição geográfica do município, que se localiza na fronteira de Mato Grosso com Rondônia, com uma população indígena significativa, em meio à floresta amazônica. A esse exemplo, citamos a notícia de 31 de julho de 2019, intitulada Programa da Biblioteca de Juína está entre os 15 melhores da América Latina, publicada no jornal Expresso MT. Também é possível encontrar a programação de eventos da BMJ ou notícias relacionadas a tal equipamento público no site do Conselho Federal e Conselhos Regionais de Biblioteconomia, entre outros. 
Marteleto (2009, p. 19) afirma que o termo pode ser entendido sob dois prismas: o de "relação com um sistema" (ex. a mediação social) ou o de "construção de sentido" (o processo interpretativo).

Quando se trata do mediador, entende-se que este aproxima sujeitos e obras culturais. O mediador cultural é um profissional cada vez mais em voga em países europeus, onde são oferecidos cursos superiores e de pós-graduação dedicados a tal modalidade de conhecimento e ofício. Esse profissional intermedia contatos entre imigrantes, refugiados e nativos de um determinado país no que respeita à língua, à cultura e à adaptação àquele local. No Brasil, usa-se a expressão mediadores culturais como referência àqueles que comentam espetáculos, atuam como contadores de histórias, dentre outros.

O conceito de mediação cultural pressupõe a ausência de algo como a dificuldade de compreensão, de acesso ou de integração a um local específico e supõe que o mediador contribua para o entendimento de algo ou para a superação de dificuldades, havendo a necessidade de ajustamentos por especialistas, e assim tem sido praticado. Apesar dessa prática que naturaliza o refugiado, o imigrante, enfim, o Outro como aquele a quem faltaria algo em relação a culturas como a ocidental (reforçando sua posição de domínio em relação a outras culturas), Martín-Barbero (1997) atualizou as pesquisas sobre mediação na América Latina por meio do estabelecimento de novas leituras das culturas populares e massivas, como rádio, cinema e televisão, na América Latina contemporânea.

A mediação, para Martín-Barbero, liga a comunicação à cultura, assim, pode-se afirmar que o mediador tem a função de comunicar conhecimentos a um dado público. Tendo em conta essa compreensão, soma-se a ela o desafio que têm as bibliotecas de passarem de prestadoras de serviços a mediadoras de mudanças de hábitos de leituras e mesmo de promover a democratização do acesso ao conhecimento. A leitura pode ser mediada das mais diversas maneiras, como temos visto pelas ações da BMJ, e de outras formas, como, por exemplo: design do livro objeto (organização da página, tipografia, produção gráfica); exposições temáticas (literatura trans ou gay, literatura de autoria feminina, autores regionais etc.); literatura para adolescentes e jovens (gêneros poético e narrativo); recepção de grupos de es- 
tudantes para apresentação do catálogo nas bibliotecas; buscas nas bases de dados (instrução sobre como fazer buscas em sistemas informáticos) etc encontro com escritores, diagramadores, ilustradores.

A propósito da leitura, Antonio Candido (2004, p.175) afirma:

Ora, se ninguém pode passar vinte e quatro horas sem mergulhar no universo da ficção e da poesia, a literatura concebida no sentido amplo (...) parece corresponder a uma necessidade universal, que precisa ser satisfeita e cuja satisfação constitui um direito.

O contato com a ficção, com a arte literária, é, pois, uma "necessidade" dos seres humanos e, como tal, precisa ser suprida. Contudo, quando não mediada por aparelhos culturais qualificados como as bibliotecas públicas, uma parcela significativa das populações dos países não terá acesso às obras. Com isso, estéticas que poderiam contribuir para sua formação humanística não conseguem fazê-lo, tendo em vista a desigualdade de acesso ao texto literário e mesmo ao informacional. A presença regular da biblioteca na vida das pessoas contribuirá para seu contínuo letramento.

Em relação ao termo letramento, para Soares:

pode-se dizer que a inserção no mundo da escrita se dá por meio da aquisição de uma tecnologia - a isso se chama alfabetização, e por meio do desenvolvimento de competências (habilidades, conhecimentos, atitudes) de uso efetivo dessa tecnologia em práticas sociais que envolvem a língua escrita - a isso se chama letramento. (SOARES, 2003, p. 90)

O letramento envolve, assim, um "conjunto de habilidades, comportamentos, conhecimentos que compõem um longo e complexo continuum" (SOARES, 2004 p. 48-49). Os mediadores de leitura ou culturais favorecem aquilo que Soares chamou continuum, ou seja, à medida que servidores como os da Biblioteca Municipal de Juína transportam livros para feiras, exposições e outros eventos, o livro, a informação e a ficção passam a fazer parte da vida daquela comunidade, mudando-lhe o perfil para o de uma comunidade de leitores que se baseia na leitura colaborativa e práticas de aproximação coletiva aos textos. Azevedo (2007:154) considera que as comunidades 
de leitores ocorrem por meio de grupos que se reúnem para ler obras, trocas de opiniões, sugestões de obras e autores de modo ativo e partilhados. Elas são alicerçadas no trabalho coletivo e participativo. Daí que as comunidades leitoras possam ser alicerçadas em ambientes, inicialmente, de mediação de leitura e, posteriormente, democráticos nos quais todos possam participar, interagir efetiva e afetivamente (Cf. VICENTE, 2010: 21).

Conforme Michèle Petit em A arte de ler (2010), experiências de deleite relacionadas com a ficção apresentam potencial de ocorrerem em momentos impensados. Por outro lado, em ocasiões em que ocorre a mediação leitora, podem ser trabalhadas habilidades de linguagem que, usadas adequadamente, conduzem à fruição. Participando de rodas de conversa, conversas com leitores, adquirimos habilidades que favorecem o trânsito entre diferentes espaços sociais. O incentivo à leitura, via mediação, envolve ainda o intermédio para o uso de novos suportes informacionais que demandam habilidades de leituras adequadas, sem as quais o potencial leitor ficará excluído da comunidade que domina tais códigos e habilidades.

Nesse sentido, reafirmamos que os equipamentos públicos são organismos vitais na mediação da informação (oral, impressa, virtual etc.) e dos saberes literários, e cumprem função importante na valoração das comunidades locais. O conceito de biblioteca parque adotado pela BMJ e o compromisso social, assim como os prêmios e os depoimentos dos leitores, aos quais se pode ter acesso por meio de vídeos disponíveis nas redes sociais, indicam que a leitura e o acesso ao livro são modos eficazes de promoção da cidadania. 


\section{REFERÊNCIAS}

BENAVENTE, Ana. A literacia em Portugal: resultados de uma pesquisa extensiva e monográfica. Fundação Calouste Gulbenkian, Lisboa, 1996.

CANDIDO, Antonio. Direito à Literatura. In: . Vários Escritos. Duas Cidades São Paulo, 2004.

GOMES, Heitor. Tendências de pesquisa sobre mediação, circulação e apropriação da informação no Brasil: estudo em periódicos e anais dos ENANCIB (2008-2009). Pesquisa Brasileira em Ciência da Informação, Brasília, DF, v.3, n.1, p.85-99, jan./dez. 2010.

MARTELETO, Regina Maria. Jovens, violência e saúde: construção de informações nos processos de mediação e apropriação de conhecimentos. RECIIS -R. Eletr. de Com. Inf. Inov. Saúde, Rio de Janeiro, v.3, n.3, p.17-24, set. 2009.

MARTÍN-BARBERO, Jesus. Dos meios às mediações: comunicação, cultura e hegemonia. Rio de Janeiro: Editora da URFJ, 1997.

MARTINS, Maria Helena. O que é Leitura. 19 ed. São Paulo: Princípios, 1994.

PEREIRA, Íris. Literacia Critica: Concepções Teóricas e Práticas Pedagógicas nos Níveis Iniciais de Escolaridade. In: AZEVEDO, Fernando \& SARDINHA, Maria da Graça (Eds.) Modelos e Práticas em Literacia. Lisboa: Lidel, 2009.

PETIT, Michèle. A arte de ler ou como resistir à adversidade. São Paulo: Editora 34, 2010.

SCRIBNER, Silvia \& COLE, Michael. The psychology of literacy. Cambridge, MA: Harvard University Press, 1981.

SOARES, Magda. As muitas facetas da alfabetização. In: Alfabetização e letramento. São Paulo: Contextos, 2003.

SOARES, Magda. Alfabetização e letramento, $2^{\circ}$ ed. São Paulo: Contexto, 2004.

TODOROV, Tzvetan. A literatura em perigo. Rio de Janeiro: DIFEL, 2009.

UNESCO. Manifesto da UNESCO para a Biblioteca Pública, Paris, 1994. Disponível em: http://archive.ifla.org/VIIs8/unesco/port.htm>. Acesso em: 10 jul. 2020

VICENTE, Cristina Maria Rebelo Salvado. Comunidade de leitores - Vinte Razões para Ler. Dissertação de Mestrado apresentada à Faculdade da Beira Interior, 2010. WILLIAMS, Reymond. Palavras-chave: um vocabulário de cultura e sociedade. Boitempo: São Paulo, 2007. 